\title{
Prostate volume effect on Gleason score upgrading in active surveillance appropriate patients
}

\author{
Emre Çamur ${ }^{1}$, Alper Cosskun ${ }^{2}$, Övünç Kavukoğlu ${ }^{3}$, Utku Can ${ }^{4}$, Önder Kara ${ }^{5}$, Arzu Develi Çamur ${ }^{6}$, \\ Kemal Sarıca $^{7}$, Kamil Fehmi Narter ${ }^{8}$ \\ ${ }^{1}$ Amasya University Sabuncuoglu Serefeddin Training And Research Hospital Urology Department, Amasya, Turkey; \\ 2 Sanlıurfa Training And Research Hospital Urology Clinic, Sanlıurfa, Turkey; \\ ${ }^{3}$ Gumushane State Hospital Urology Clinic, Gumushane, Turkey; \\ ${ }^{4}$ Erzurum Training And Research Hospital Urology Clinic, Erzurum, Turkey; \\ ${ }^{5}$ Kocaeli University Medical Faculty Hospital Urology Clinic, Kocaeli, Turkey; \\ ${ }^{6}$ Suluova State Hospital, Internal Medicine Clinic, Amasya, Turkey; \\ ${ }^{7}$ Kafkas University Training And Research Hospital Urology Clinic, Kars, Turkey; \\ ${ }^{8}$ Acıbadem Mehmet Ali Aydınlar University Hospital Urology Clinic, Istanbul, Turkey.
}

\begin{abstract}
Summary Introduction: Gleason Score (GS) upgrading rates in the literature are reported to be around $33-45 \%$. The relationship between prostate volume and GS upgrading should be defined, aiming to reduce upgrading rates in patients with low risk groups who are eligible for active surveillance (AS) or minimally invasive treatment, by varying biopsy cores, or lengths of cores according to prostate volumes. In this regard, the aim of our study was to establish the relationship between prostate volume and GS upgrading.

Materials and methods: We retrospectively analyzed the medical records of 78 patients, who were appropriate for AS between 2011-2016 at our hospital. Inclusion criteria were patient age under 65 years, PSA level under $10 \mathrm{ng} / \mathrm{ml}, \mathrm{GS}(3+$ $3)$ or $(3+4)$, and 3 or less positive cores, clinical stages $\leq T 2$. GS increase in radical prostatectomy specimen was considered as 'upgrading' and in addition, score reported by biopsy as $3+$ 4 but in surgical specimen as $4+3$ were also considered as 'upgrading. The effect of prostate volume on Gleason grade upgrading was examined by calculating upgrading rates separately for patients with prostate volume $30 \mathrm{ml}$ or less, those with 30 to $60 \mathrm{ml}$, and those over $60 \mathrm{ml}$.

Results: As a result of the analysis of the data, upgrading was seen in $35(44.8 \%)$ of 78 patients included in the study. In the cohort mean prostate volume was $49.8( \pm 26.3) \mathrm{ml}$. Twenty-two patients $(28.2 \%)$ had prostate volume $30 \mathrm{ml}$ or less, $34(43.6 \%)$ 30 to $60 \mathrm{ml}$, and $22(28.2 \%) 60 \mathrm{ml}$ or more. The patients were divided into two groups as those with and without GS upgrading. Between the groups prostate volume and prostate volume range $(0-30 / 31-60 />60)$ were not significantly different ( $p$ value $>0.05$ )

Conclusions: Gleason grade upgrading causes patients to be classified in a lower risk group than they actually are, and may lead to inappropriate treatment. This condition has a direct effect on the decision of active surveillance. Therefore, it is important to define the factors that can predict GS upgrading in active surveillance appropriate patients. In this study, we found that prostate volume has no significant effect on upgrading in active surveillance appropriate patients.
\end{abstract}

KEY WORDS: Prostate cancer; Gleason score; Upgrading; Active surveillance.

Submitted 5 January 2019; Accepted 11 March 2019

\section{INTRODUCTION}

Prostate cancer is the second most common cancer worldwide and the fifth most common cause of cancerrelated deaths. Because of this reason, there are lots of studies on prostate cancer (1-2).

Active surveillance (AS) has been defined in the appropriate group of patients for low-risk prostate cancer. Gleason Score (GS) is the most important criteria for patient selection for AS and used in the nomograms. In most studies and nomograms (3+3) GS in the biopsy is used as an inclusion criterium. Recently, researchers have included some eligible patients with a biopsy GS 3 +4 to their studies (3-6).

In patients, considered AS option, all pathological data, including GS are dependent on prostate needle biopsy. So that, the accuracy of the GS in needle biopsies is very important for this patient groups. However, there may be a significant difference between GSs in needle biopsies and radical prostatectomy specimens. If the score in prostatectomy specimen is higher than needle biopsy, that is defined as 'upgrading', if it is lower, 'downgrading' is mentioned. Upgrading rates in the literature are reported to be around 33-45\% (7).

Because of upgrading, patients who are not actually suitable for AS can be recommended with inappropriate treatment options. The reason for this high pathological disruption seems to be that less than $1 \%$ of the prostate tissue can be sampled with needle biopsy. Assessment in such a small tissue volume can cause tumor tissue to be undetectable or even missed (8-9). This is supported by studies showing that rates of upgrading in needle biopsies of enlarged prostate are lower (10-14). In most of previous studies, an inverse correlation was found between prostate volume and upgrading rates (15-17). Kulkarni et al. have not found significant relationship between prostate volume and upgrading rates, in a retrospective study published in 2006 in which they reviewed 369 patients (18).

If the relationship between prostate volume and GS upgrading can be assessed, it may be aimed to reduce upgrading rates in patients with low risk groups who are

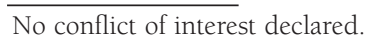


eligible for active follow-up or minimally invasive treatment, by varying biopsy cores, or lengths of cores according to their prostate volumes.

In this regard, the aim of our study is to establish the relationship between prostate volume and GS upgrading.

\section{Materials AND Methods}

We retrospectively analyzed the medical records of 78 patients, who are appropriate for AS between 2011-2016 at our Hospital (Dr. Lütfi Kirdar Kartal Training and Research Hospital, Istanbul, Turkey).

Age, prostate-specific antigen (PSA), prostate volume, total number of cores in the preoperative biopsy, cancer positive core number in the biopsy, GS in the biopsy report, clinical stage, GS in prostatectomy specimen, presence of prostatic intraepithelial neoplasia (PIN), extracapsular extension (ECE), vascular invasion, surgical margin status, perineural invasion (PNI), seminal vesicle involvement (SVI) were evaluated. Study protocol was approved by Ethics Committee of Dr.Lütfi Kirdar Training and Research Hospital. Inclusion criteria were patient age under 65 years, PSA level under $10 \mathrm{ng} / \mathrm{ml}$, GS $(3+3)$ or $(3+4)$, and 3 or less positive cores, clinical stages $\leq \mathrm{T} 2$. Prostate volumes were measured transrectally during biopsy, all biopsies were 12 cores and pathologic examination was performed by two experienced uro-pathologists in our hospital. GS, total cores, and cancer positive core numbers were noted in the biopsy specimens that detected adenocarcinoma. The length or percentage of the cancer positive tissue couldn't found in most reports. GS, PIN, surgical marginal status, PNI, SVI, ECE, presence of vascular invasion were registered. Biopsy and prostatectomy specimens were evaluated according to 2005 International Society of Uro-pathologists (ISUP) modified Gleason system. GS increase in radical prostatectomy specimen was assessed as 'upgrading' and in addition also cases in which the score reported by biopsy was $3+4$ and the score found in the specimen was $4+3$ were evaluated as 'upgrading'. The effect of prostate volume on Gleason grade upgrading was examined. Patients initially were divided into GS upgrading or not. These groups were compared in terms of age, PSA value, prostate volume, number of total biopsy cores, number of positive cores, clinical stages, surgical margin status, and SVI, presence of ECE, PIN, PNI, and vascular invasion.

Upgrading rates were calculated separately for patients with prostate volume $30 \mathrm{ml}$ or less, those with 30 to $60 \mathrm{ml}$, and those over $60 \mathrm{ml}$. In the descriptive statistics of the data, mean, standard deviation, median lowest, highest, frequency and ratio values were used. The distribution of the variables was measured with the Kolmogorov Simirnov test. Mann-Whitney U test was used for quantitative independent data analysis. Chi-square test was used for the analysis of qualitative independent data and SPSS 22.0 (Statistical Package for the Social Sciences) program was used in the analysis. P value below 0.05 were considered statistically significant $(\mathrm{p}<0.05)$.

\section{RESULTS}

As a result of the analysis of the data, upgrading was seen in $35(44.8 \%)$ of 78 patients included in the study.

The mean age of patients included in the study was 60.6 $( \pm 4.4)$ years, and the mean PSA was $6.0( \pm 2.2) \mathrm{ng} / \mathrm{ml}$. According to needle biopsy reports, 65 patients $(83.3 \%)$ had a GS of $(3+3)$ and 13 patients $(16.7 \%)$ had $(3+4)$. In cohort mean prostate volume was $49.8( \pm 26.3) \mathrm{ml}$. Twenty-two patients (28.2\%) have prostate volume 30 $\mathrm{ml}$ or less, $34(43.6 \%) 30$ to $60 \mathrm{ml}$, and $22(28.2 \%) 60$ $\mathrm{ml}$ or more. The demographic and clinico-pathological

\section{Table 1.}

Demographics and clinico-pathological outcomes of the patients undergoing radical prostatectomy.

\begin{tabular}{lccc|}
\hline & Range & Median & Mean+/-SD \\
\hline Age & $46.0+/-65.0$ & 61.5 & $60.6+/-4.4$ \\
\hline PSA & $2.3-10.0$ & 5.7 & $6.0+/ 2.2$ \\
\hline Prostate volume & $14-135$ & 43.0 & $49.8+/-26.3$ \\
\hline Prostate volume & $0-30$ & 22 & $28.2 \%$ \\
& $31-60$ & 34 & $43.6 \%$ \\
& $>60$ & 22 & $28.2 \%$ \\
\hline Gleason Score Biopsy & $3+3$ & 65 & $83.3 \%$ \\
& $3+4$ & 13 & $16.7 \%$ \\
\hline Stage & $\mathrm{T} 2 \mathrm{c}$ & 26 & $33.3 \%$ \\
& $\mathrm{~T} 2$ & 52 & $16.7 \%$ \\
\hline No positive cores & $\mathrm{I}$ & 31 & $39.7 \%$ \\
& $\mathrm{II}$ & 17 & $21.8 \%$ \\
& $\mathrm{III}$ & 30 & $38.5 \%$ \\
\hline Gleason Score Specimen & $3+3$ & 38 & $48.7 \%$ \\
& $3+4$ & 25 & $32.1 \%$ \\
& $4+3$ & 9 & $11.5 \%$ \\
& $4+4$ & 5 & $6.4 \%$ \\
& $4+5$ & 1 & $1.3 \%$ \\
\hline Upgrade & $(-)$ & 43 & $44.8 \%$ \\
& $(+)$ & 35 & $55.1 \%$ \\
\hline
\end{tabular}

Table 2.

Comparison of the upgraded and non-upgraded groups.

\begin{tabular}{|lcccccc|}
\hline & \multicolumn{2}{c}{ Upgrade (-) } & \multicolumn{2}{c}{ Upgrade (+) } & $\mathbf{p}$ \\
\hline & & Mean & Median & Mean & Median & \\
\hline Age & & $59+/-4.8$ & 61 & $61.4+/-3.8$ & 62 & $0.183 \mathrm{~m}$ \\
\hline PSA & & $5.8+/-2.2$ & 5.4 & $6.2+/-2.2$ & 5.9 & $0.529 \mathrm{~m}$ \\
\hline Prostate volume & & $53.1+/-28$ & 46 & $45.8+/-23.9$ & 39 & $0.303 \mathrm{~m}$ \\
\hline Prostate volume & $0-30$ & 12 & $27.9 \%$ & 10 & $28.6 \%$ & $0.604 \mathrm{x}^{2}$ \\
& $31-60$ & 17 & $39.5 \%$ & 17 & $48.6 \%$ & \\
& $>60$ & 14 & $32.6 \%$ & 8 & $22.9 \%$ & \\
\hline GS biopsy & $3+3$ & 35 & $81.4 \%$ & 30 & $85.7 \%$ & $0.611 \mathrm{x}^{2}$ \\
& $3+4$ & 8 & $18.6 \%$ & 5 & $14.3 \%$ & \\
\hline $\mathbf{N}^{\circ}$ positive cores & $\mathrm{I}$ & 18 & $41.9 \%$ & 13 & $37.1 \%$ & $0.747 \mathrm{x}^{2}$ \\
& $\mathrm{II}$ & 8 & $18.6 \%$ & 9 & $25.7 \%$ & \\
& $\mathrm{III}$ & 17 & $39.5 \%$ & 13 & $37.1 \%$ & \\
\hline GS specimen & $3+4$ & 5 & $11.6 \%$ & 20 & $57.1 \%$ & $0.000 \mathrm{x}^{2}$ \\
& $4+3$ & 0 & 0 & 9 & $25.7 \%$ & \\
& $4+4$ & 0 & 0 & 5 & $14.3 \%$ & \\
& $4+5$ & 0 & 0 & 1 & $2.9 \%$ & \\
\hline m: Mann-Whitney U test; $x^{2}:$ Chi-Square test. & & & & \\
\hline
\end{tabular}


outcomes of the patients included in the study are summarized in the Table 1.

The patients were divided into two groups as those with and without GS upgrading. In the analysis, no significant difference was observed between these groups in terms of age, PSA values, biopsy GS, number of positive biopsy cores, clinical stage ( $p>0.05)$.

GS $(3+3)$ was significantly higher in non-upgrading group ( $p>0.05$ ) (Table 2).

Between the groups with different prostate volume (030/31-60/> 60) no significant difference was found ( $p$ value $>0.05)$ (Table 2).

\section{Discussion}

Treatment options in prostate cancer differ according to defined risk groups. Low risk patients have better prognosis than middle and high risk group and lower biochemical recurrence rates after radical prostatectomy.

In these patients, active follow-up, brachytherapy and focal therapies are used in order to avoid the complications and side effects of radical prostatectomy or radiotherapy $(17,19-20)$.

PSA level, clinical stage and GS are used to determine these risk classification (21-22). GS is the most important prognostic factor of prostate cancer risk for classification and choice of treatment options (16, 22-23). Accurate determination of patient's risk group and GS at the time of diagnosis is important in order to choose the appropriate treatment options.

However, there are significant pathological differences between needle biopsies and radical prostatectomy specimens such as GS upgrading in $33-45 \%$. This high rate led investigators to examine the factors that might be effective to predict upgrading.

PSA level, number of cores taken, number of positive cores are some of these factors. Also there are several studies on the effect of prostate volume on GS upgrading. $(10,15,24-27)$.

In 2008 Turley et al. investigated 586 patients retrospectively. In this study, GS elevation rate was found to be increased as prostate volume decreased (28).

In a study that Moon et al. reviewed 107 patients retrospectively demonstrating that 12 or less number of cores in the biopsy and prostate volume of $36.5 \mathrm{ml}$ or less were a predictive factor of GS upgrading $(15,29)$.

Davies et al. published a retrospective study on prostate volume effect on GS upgrading in 2011. In this large study, medical records of 1.251 low-risk patients were retrospectively investigated and it was found that risk of GS upgrading was more than fifty percent in subjects with prostate volume $36 \mathrm{~cm}^{3}$ compared to those with 58 $\mathrm{cm}^{3}$ (16).

Similarly, Chung et al., in a retrospective study of 247 patients published in 2013, reported that patients with prostate volumes of $25 \mathrm{~cm}^{3}$ or lower had a GS upgrading risk of 2.7 times more than patients with a prostate gland volume of $40 \mathrm{~cm}^{3}$ or more (15).

However, in a retrospective study of 369 patients, Kulkarni et al. reported no significant relationship between prostate volume and GS upgrading (18).

Gleason grade elevation is most important in active sur- veillance. However, a study that examined the effect of prostate volume on GS upgrading in active surveillance appropriate patients has not been previously mentioned in the literature.

In this study, 78 patients with active monitoring were included. Inclusion criteria were patient age under 65 years, PSA level under $10 \mathrm{ng} / \mathrm{ml}$, GS $3+3$ or $3+4$ and 3 or less positive cores, clinical stage $\leq \mathrm{T} 2$. Prostate volume effect on GS upgrading in active surveillance appropriate patients was examined, and patients with prostate volume of $30 \mathrm{ml}$ or less, between $30 \mathrm{ml}$ and $60 \mathrm{ml}$ and greater than $60 \mathrm{ml}$ were compared.

According to our results prostate volume found to have no significant effect on GS upgrading in patients who are eligible for active surveillance. Retrospective nature and small number size of this study, and the calculation of prostate dimensions by different clinicians were the limitations of our study.

\section{Conclusions}

Treatment alternatives in prostate cancer may differ according to risk groups. So that it is important to classify patients in the correct risk group.

Gleason grade upgrading causes patients to be classified in a lower risk group than they actually are, and may lead to inappropriate treatment. This situation has a direct effect on the decision of active surveillance. Therefore, it is important to define the factors that can predict GS upgrading in active surveillance appropriate patients. In this study, we found that prostate volume has no significant effect on upgrading in active surveillance appropriate patients.

\section{Compliance With ethical STANDARDS}

Funding: This study was not funded.

Conflict of Interest: All authors declare that they have no conflict of interest.

Ethical approval: All procedures performed in studies involving human participants were in accordance with the ethical standards of the institutional and/or national research committee and with the 1964 Helsinki declaration and its later amendments or comparable ethical standards.

Informed consent: Informed consent was obtained from all individual participants included in the study.

\section{REFERENCES}

1. International Agency for Research on Cancer (IARC) Cancer Fact Sheets - Prostate Cancer - Source Globoscan 2018 http://globocan iarc fr/Pages/fact_sheets_cancer aspx (20 March 2014, date last accessed). 2014.

2. Humphrey P, Schuz J. Cancers of the male reproductive organs. World Cancer Report Lyon: World Health Organization. 2014; pp 453-64.

3. Thomsen FB, Brasso K, Klotz LH, et al. Active surveillance for clinically localized prostate cancer-A systematic review. J Surg Oncol. 2014; 109:830-5.

4. Loeb S, Bruinsma SM, Nicholson J, et al. Active surveillance for 
prostate cancer: a systematic review of clinicopathologic variables and biomarkers for risk stratification. Eur Urol. 2015; 67:619-26.

5. Ploussard G, Isbarn H, Briganti A, et al. (editors) Can we expand active surveillance criteria to include biopsy Gleason 3+ 4 prostate cancer? A multi-institutional study of 2,323 patients. Urol Oncol. 2015; 33:71.e1-9.

6. Schiavina R, Borghesi M, Brunocilla E, et al. The biopsy Gleason score $3+4$ in a single core does not necessarily reflect an unfavourable pathological disease after radical prostatectomy in comparison with biopsy Gleason score 3 + 3: looking for larger selection criteria for active surveillance candidates. Prostate Cancer Prostatic Dis. 2015; 18:270-5.

7. Bostwick DG, Cheng L. Urologic surgical pathology. 3 ed: Elsevier/Saunders; 2014. p. 408-531.

8. Partin A. Prostat tümörlerinin patolojisi In: Yaman Ö (ed.) Campbell Walsh Üroloji 10 ed: Saunders/Günes Tip Kitabevleri 2014: pp 2726-34.

9. Epstein JI. Diagnosis and reporting of limited adenocarcinoma of the prostate on needle biopsy. Mod Path. 2004; 17:307-15.

10. Freedland SJ, Kane CJ, Amling CL, et al. Upgrading and downgrading of prostate needle biopsy specimens: risk factors and clinical implications. Urology. 2007; 69:495-9

11. Pinthus JH, Witkos M, Fleshner N, et al. Prostate cancers scored as Gleason 6 on prostate biopsy are frequently Gleason 7 tumors at radical prostatectomy: implication on outcome. J Urol. 2006; 176:979-84.

12. King CR, McNeal JE, Gill H, Presti JC. Extended prostate biopsy scheme improves reliability of Gleason grading: implications for radiotherapy patients. Int J Radiat Oncol Biol Phys. 2004; 59:38691.

13. Emiliozzi P, Maymone S, Paterno A, et al. Increased accuracy of biopsy Gleason score obtained by extended needle biopsy. J Urol. 2004; 172:2224-6.

14. San Francisco IF, DeWolf WC, Rosen S, et al. Extended prostate needle biopsy improves concordance of Gleason grading between prostate needle biopsy and radical prostatectomy. J Urol. 2003; $169: 136-40$

15. Chung MS, Lee SH, Lee DH, Chung BH. Is small prostate volume a predictor of Gleason score upgrading after radical prostatectomy? Yonsei Med J. 2013; 54:902-6.

16. Davies JD, Aghazadeh MA, Phillips S, et al. Prostate size as a predictor of Gleason score upgrading in patients with low risk prostate cancer. J Urol. 2011; 186:2221-7.

17. Kim KH, Lim SK, Shin TY, et al. Upgrading of Gleason score and prostate volume: a clinicopathological analysis. BJU Int. 2013; 111:1310-6.

18. Kulkarni GS, Al-Azab R, Lockwood G, et al. Evidence for a biopsy derived grade artifact among larger prostate glands. J Urol. 2006; 175:505-9.

19. Partin AW, Yoo J, Carter HB, et al. The use of prostate specific antigen, clinical stage and Gleason score to predict pathological stage in men with localized prostate cancer. J Urol. 1993; 150:1104.

20. D'Amico AV, Whittington R, Malkowicz SB, et al. Biochemical outcome after radical prostatectomy, external beam radiation therapy, or interstitial radiation therapy for clinically localized prostate cancer. JAMA. 1998; 280:969-74.

21. Mottet N, Bellmunt J, Briers E, et al. Diagnostic evaluation.
EAU-ESTRO-SIOG guidelines on prostate cancer. EAU Guidelines Office. Arnhem, The Netherlands, 2016, pp 14-27.

22. D'Amico AV, Moul J, Carroll PR, et al. Cancer specific mortality after surgery or radiation for patients with clinically localized prostate cancer managed during the prostate-specific antigen era. $J$ Clin Oncol. 2003; 21:2163-72.

23. Zincke H, Bergstralh EJ, Blute ML, et al. Radical prostatectomy for clinically localized prostate cancer: long-term results of 1,143 patients from a single institution. J Clin Oncol. 1994; 12:2254-63.

24. Kulkarni GS, Lockwood G, Evans A, et al. Clinical predictors of gleason score upgrading. Cancer. 2007; 109:2432-8.

25. Hong SK, Han BK, Lee ST, et al. Prediction of Gleason score upgrading in low-risk prostate cancers diagnosed via multi $(\geq 12)$ core prostate biopsy. World J Urol. 2009; 27:271-6.

26. Miyake H, Kurahashi T, Takenaka A, et al. Improved accuracy for predicting the Gleason score of prostate cancer by increasing the number of transrectal biopsy cores. Urol Int. 2007; 79:302-6.

27. Moussa AS, Li J, Soriano M, et al. Prostate biopsy clinical and pathological variables that predict significant grading changes in patients with intermediate and high grade prostate cancer. BJU Int. 2009; 103:438.

28. Turley RS, Hamilton RJ, Terris MK, et al. Small transrectal ultrasound volume predicts clinically significant Gleason score upgrading after radical prostatectomy: results from the SEARCH database. J Urol. 2008; 179:523-8.

29. Moon SJ, Park SY, Lee TY. Predictive factors of Gleason score upgrading in localized and locally advanced prostate cancer diagnosed by prostate biopsy. Korean J Urol. 2010; 51:677-82.

\section{Correspondence}

Emre Çamur, MD (Corresponding Author)

emre.camur@outlook.com

Amasya University Sabuncuoglu Serefeddin Training And Research Hospital Urology Department, Amasya (Turkey)

Alper Coskun, MD

dr.alper05@gmail.com

Sanliurfa Training and Research Hospital Urology Clinic, Sanlıurfa (Turkey)

Övünç Kavukoğlu, MD

ovunckavukoglu@hotmail.com

Gumushane State Hospital Urology Clinic, Gumushane (Turkey)

Utku Can, MD

utkucan99@yahoo.com

Erzurum Training and Research Hospital Urology Clinic, Erzurum (Turkey)

Onder Kara, MD

onerkara@yahoo.com

Kocaeli University Medical Faculty Hospital Urology Clinic, Kocaeli (Turkey)

Arzu Develi Çamur, MD

develiarzu@hotmail.com

Suluova State Hospital, Internal Medicine Clinic, Amasya (Turkey)

Kemal Sarica, MD

saricakemal@gmail.com

Kafkas University Training and Research Hospital Urology Clinic,

Kars (Turkey)

Kamil Fehmi Narter, MD

fehminarter66@gmail.com

Acıbadem University Hospital Urology Clinic, Istanbul (Turkey) 